E3S Web of Conferences 1, 23007 (2013)

DOI: $10.1051 / \mathrm{e} 3$ sconf/20130123007

(C) Owned by the authors, published by EDP Sciences, 2013

\title{
An overview of atmospheric mercury monitoring at Auchencorth Moss, the UK EMEP Supersite in southern Scotland: trends, patterns and a source analysis
}

\author{
J. Kentisbeer, S. Leeson, H. Malcolm, I. Leith and J. N. Cape \\ Centre for Ecology \& Hydrology, Bush Estate, Penicuik, Midlothian, EH26 0QB (jkbeer@ceh.ac.uk)
}

\begin{abstract}
Speciated atmospheric mercury has been measures semi-continuously at the Auchencorth Moss field site in southern Scotland since 2004. Here we present an analysis of the data from 2009 to 2011 for the three species: elemental, gaseous oxidized (GOM) and particulate bound (PBM) mercury. Measurements of elemental mercury were made using the Tekran 2537A analyser and the Tekran 1130 and 1135 speciation units were used to collect GOM and PBM respectively. The data shows no upward or downward trend for elemental mercury, with yearly average concentrations between 1.3 and $1.5 \mathrm{ng} \mathrm{m}^{-3}$. We will continue the work started in Kentisbeer et al, 2010 to analyse the effect of wind direction on the mercury species, making further of air mass back trajectories and introducing cluster analysis to investigate the effects of longer range transport to the site.
\end{abstract}

Key words: elemental mercury, gaseous oxidized mercury, particulate bound mercury, monitoring

\section{Introduction}

Global measurements of mercury in the atmosphere were recently reviewed by Sprovieri et al., $2010^{1}$. They noted that though there have been several decades of continuous and campaign based mercury measurements, a coordinated observational network for $\mathrm{Hg}$ does not exist and there are still many unanswered questions. This paper reports a three year dataset for atmospheric mercury measurements made at one of the UK measurement "Supersites": Auchencorth Moss, Scotland, UK. Measurements were made semi-continuously between 2009 and 2011, and are on-going.

The monitoring work carried out at Auchencorth Moss is part of the UK EMEP measurement delivery programme $^{2}$ (is in parallel with other global network studies, as part of the Global Mercury Observation System. Mercury mostly exists in its elemental form $\left(\mathrm{Hg}^{0}\right)$ in the atmosphere $(\sim 95 \%)$ and is relatively volatile and largely unreactive meaning that it has low dry and wet deposition rates. There are many forms of mercury in the atmosphere, just at low concentrations. Particulate bound mercury (PBM) and gaseous oxidised mercury (GOM) also exist and are much more reactive, leading to PBM and GOM having much shorter atmospheric lifetimes than $\mathrm{Hg}^{0}$ and in particular being efficiently removed through wet and dry deposition processes.
Understanding mercury in the environment is important for several reasons: it is an anthropogenically produced pollutant, with sources including coal burning, mining activities and other industrial processes; its atmospheric chemistry is complex. Two interests for example, are the multiple forms of mercury and the interactions of these chemical forms with atmospheric oxidants and how the volatility of $\mathrm{Hg}^{0-}$ drives a distillation of $\mathrm{Hg}$ to the Polar Regions.

This paper presents a summary of the measurements made in the context of other global monitoring activities and outlines the temporal variability of $\mathrm{Hg}^{0}, \mathrm{PBM}$ and GOM for the Auchencorth Moss site and simple back trajectory/ source analyses.

\section{Materials and Methods}

The Auchencorth Moss field site is operated by CEH and mostly funded by DEFRA UK Government Department. It is located about $20 \mathrm{~km}$ south-west of Edinburgh $(55.450 \mathrm{~N}, 3.150 \mathrm{~W})$. This is a rural, upland peat site with a large, uniform fetch in a remote location, comprising assorted species of grass, heather and mosses. The surrounding land areas are farmed for cattle and sheep, as well as there being some wooded areas. The field site was established in 1995, and is now operated as a level III 
EMEP site, part of the co-operative programme for monitoring and evaluation of long-range transmission of air pollutants in Europe. ${ }^{3}$

The Tekran mercury speciation system (Model 2537A, 1130 and 1135, Tekran Inc.), is used to measure $\mathrm{Hg}^{0}$, GOM and PBM in air. Air was sampled at a total flow rate of $101 \mathrm{~min}^{-1}$. The air was sampled using an external inlet initially at $0.9 \mathrm{~m}$ (2009-10) and subsequently $4 \mathrm{~m},(2011)$. The change in height was put in place to remove the potential for deposition of GOM and PBM to surfaces and achieve a more representative background for elemental mercury. GOM and PBM are stripped from the sampled air stream into "speciation units". A flow of $0.91 \mathrm{~min}-1$ is sub-sampled by the 2537A for analysis of $\mathrm{Hg}^{0}$. The speciation units are sequentially desorbed during the analysis phase of the instrument cycle. The 2537A analyser uses an automated dual channel amalgamation system with a resolution of 5 minutes, allowing continuous sampling of ambient air and the pre-concentration of mercury by adsorption onto one of the two gold cartridges, whilst the other cartridge is simultaneously desorbed and analysed.

Air mass back trajectories are calculated using the HYSPLIT Trajectory Model (Hybrid Single Particle Lagrangian Integrated Trajectory Model) and cluster analysis is based on those back-trajectories. The OpenAir software package ${ }^{4}$ is used through the $\mathrm{R}$ Statistical package $^{5}$ to investigate the statistics of the air mass history. From these results the influence of local and regional pollution sources and also the role of atmospheric processing can be assessed.

\section{Results and Discussion}

For 2009, 2010 and 2011 the mean annual concentration of $\mathrm{Hg}^{0}$ was $1.36,1.45$ and $1.38 \mathrm{ng} . \mathrm{m}^{-3}(\mathrm{sd}=0.23,0.13$ and $0.18 \mathrm{ng} . \mathrm{m}^{-3}$ respectively). For PBM, the mean annual concentrations for 2009 and 2010 were 3.63 and 0.68 pg $\mathrm{m}-3$ ( $\mathrm{sd}=5.11$ and $5.23 \mathrm{pg} \cdot \mathrm{m}^{-3}$ respectively). Mean annual GOM concentrations for 2009 and 2010 were 0.3 and $0.57 \mathrm{pg} \mathrm{m}-3$ ( $\mathrm{sd}=1.09$ and $2.26 \mathrm{pg} \mathrm{m}^{-3}$ respectively). The measurement time series are shown in Figure 1. (Note that there are several data gaps due to instrument maintenance/breakdown).

Several episodic events can be seen in the time series, for example $15^{\text {th }}$ May 2009 and $5^{\text {th }}$ May 2010 which will be looked through detailed analysis of air mass back trajectories and concurrent variation of other atmospheric species at the site. A first assessment of the influence of wind direction on the concentrations of $\mathrm{Hg}^{0}$, GOM and PBM was carried out in Kentisbeer et al, $2011^{6}$ and is shown in Figure 2. $\mathrm{Hg}^{0}$ concentration is largely independent of wind direction. The variation of PBM and GOM concentrations with wind direction show some significant directionality with spikes to the north west and south east. Local influences and longer range transport will be considered during the analysis.
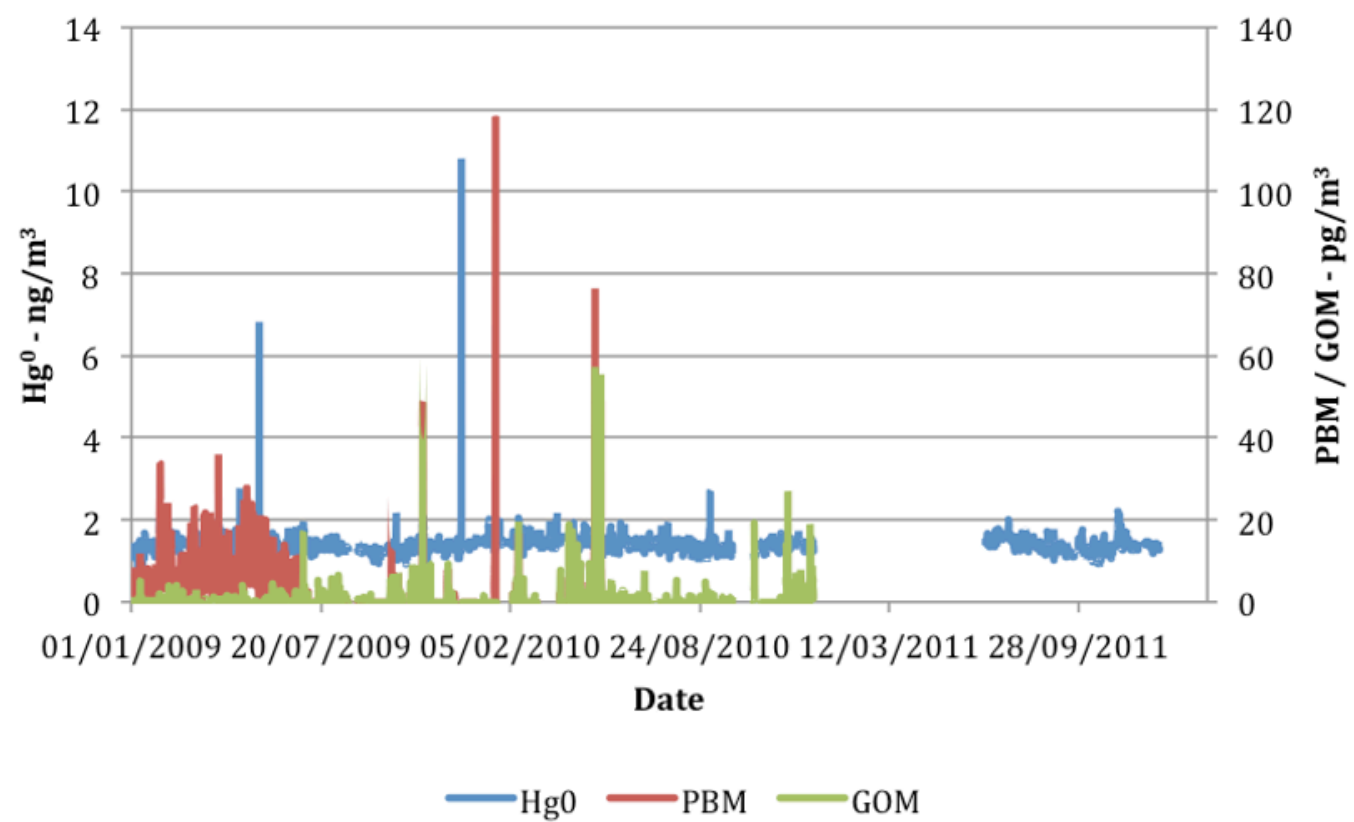

Fig. 1. Long term trend in the three species of atmospheric mercury monitored at Auchencorth Moss. Data gaps during 2011 for all three species were due to instrument maintenance and repair. 


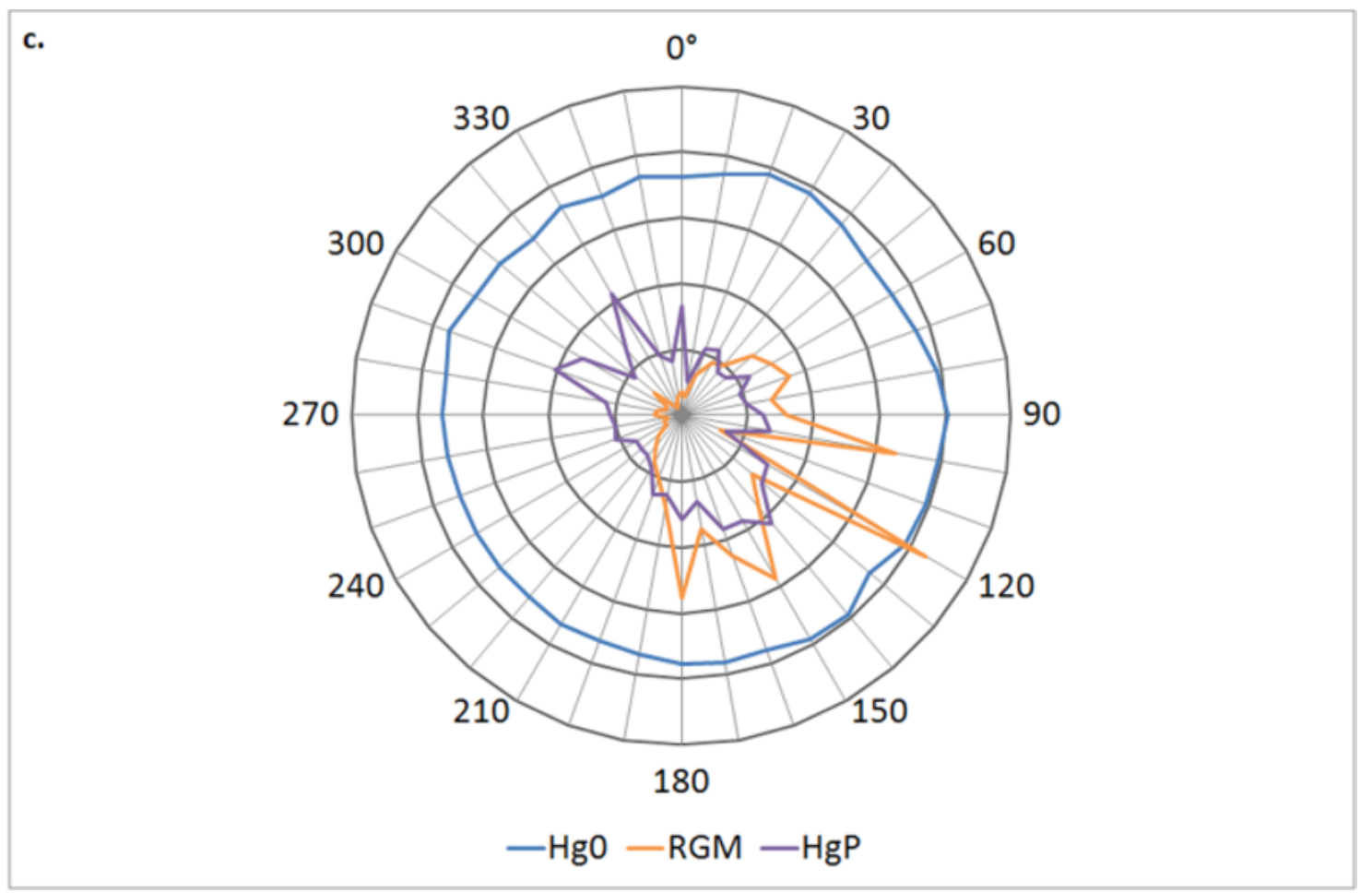

Fig. 2. Wind Rose showing the variation of chemical composition as a function of wind direction for atmospheric mercury at Auchencorth Moss (2005-2008) [Kentisbeer et al, 2010 ${ }^{6}$ ]

\section{Conclusion}

From the three datasets, Auchencorth Moss has been shown to be a typical background site for monitoring background atmospheric mercury levels in the UK. The dataset presented here is unique to the UK and will show thorough analysis, a detailed understanding of mercury in the UK and more regionally in Europe to be further established. The results will be available to assess in conjunction with the UK Heavy Metals Network low resolution mercury monitoring activity

\section{References}

1. Sprovieri et al, A review of worldwide atmospheric mercury measurements, Atmospheric Chemistry and Physics2010, 10. 8425-8265

2. Cape, J.N.. 2010 Operation of EMEP 'supersites' in the United Kingdom. Annual report for 2008. Edinburgh, NERC/Centre for Ecology \& Hydrology, 112pp. (CEH Project Number: C03087)

3. http://emep.int

4. http://www.openair-project.org/Default.aspx

5. http://www.r-project.org/

6. Kentisbeer, J et al, An analysis of total gaseous mercury (TGM) concentrations across the UK from a rural sampling network, J. Environmental Monitoring 2011, 13 (6). 1653-1661 